\title{
VACTERL-H SYNDROME - A CASE REPORT
}

\section{Dr. Priya Singh ${ }^{1}$, Prof. Dr. Ghazi Sharique Ahmad ${ }^{2}$, Prof. Dr. Ahmad Rizwan Karim ${ }^{3}$}

${ }^{1}$ Post Graduate Trainee, Department of Pediatrics, Katihar Medical College, Katihar, Bihar, India.

${ }^{2}$ Head Department of Pediatrics, Katihar Medical College, Katihar, Bihar, India.

${ }^{3}$ Department of Radiology, Katihar Medical College, Katihar, Bihar, India.

Article Info: Received 11 August 2019; Accepted 11 September. 2019

DOI: https://doi.org/10.32553/ijmbs.v3i9.526

Address for Correspondence: Prof. Dr. Ghazi Sharique Ahmad, Head Department of Pediatrics, Katihar Medical College, Katihar, Bihar, India.

Conflict of interest: No conflict of interest.

\section{Abstract}

The exact cause of VACTERL association is unknown; most cases occur randomly, for no apparent reason. In rare cases, VACTERL association has occurred in more than one family member. VACTERL association is an association of birth defects that affects multiple parts of the body. It includes vertebral or vascular anomalies, anal atresia, cardiac defects, tracheoesophageal - fistula/esophageal atresia, renal defects, and limbs defects. Other features may include (less frequently) growth deficiencies and failure to thrive; facial asymmetry (hemifacial microsomia); external ear malformations; intestinal malrotation; and genital anomalies. Intelligence is usually normal.

The diagnosis of VACTERL-H Syndrome is majorly based upon the complete physical examination and a few specialized tests to ascertain the features of the syndrome. The treatment of VACTERL-H is directed towards the specific symptoms that are apparent in each individual, which often varies greatly. The management of patients with VACTERL/VATER association typically centers around surgical correction of the specific congenital anomalies (typically anal atresia, certain types of cardiac malformations, and/or tracheo-esophageal fistula) in the immediate postnatal period, followed by long-term medical management of sequelae of the congenital malformations. If optimal surgical correction is achievable, the prognosis can be relatively positive. Hence early diagnosis and early interventions are needed to prevent morbidity and mortality.

Key words: VACTERL-H syndrome, congenital malformations, clinical examinations

\section{Introduction:}

Incidence of VACTERL syndrome is very rare, 1 -9 in 100,000 live born.[1] VACTERL syndrome does not involve neuro-cognitive impairment unless associated with hydrocephalus known as VACTERL-H syndrome. [2]

Incidence of VACTERL-H syndrome is reported only in 10 families till date. [3]

VACTERL syndrome is defined [1] as the presence of any 3 of the congenital malformations namely vertebral defects, anorectal malformations, cardiac defects, tracheo-esophageal fistula, renal anomalies, limb defects. Clinical and laboratory based analysis should not yield evidence of an alternative diagnosis. [1]The diagnosis of VACTERL-H syndrome was based on the cluster of findings in this case (Table 1).
Table 1:

\begin{tabular}{|l|l|}
\hline VACTERL SYNDROME & DIAGNOSTIC FINDING \\
\hline Vertebral defects & Hemivertebrae. Scoliosis. \\
\hline Anorectal malformations & $\begin{array}{l}\text { Anal atresia corrected by } \\
\text { anorectoplasty. }\end{array}$ \\
\hline Cardiac defects & -Not detected- \\
\hline Tracheo Esophageal fistula & -Not detected- \\
\hline Renal anomalies & Left renal agenesis. \\
\hline Limb abnormalities & Right Club foot \\
\hline & + Hydrocephalus (obstructive) \\
\hline
\end{tabular}

While typically defined by the presence of radial anomalies or thumb aplasia/hypoplasia; other limb anomalies, such as distal tibial aplasia, clubfoot, hallucal deficiency and pre-axial polydactyly, have also been described in VACTERL cases. [1,6]. We were studied a case of VACTERL-H syndrome in department of Pediatrics, Katihar Medical College 
and Hospital Katihar, Bihar, India during a month of August 2017.

\section{METHODS \& OBSERVATIONS}

A 11 months old female patient was brought in the Department of Pediatrics, Katihar Medical College and Hospital, Katihar, Bihar with difficulty in passing stools for 10 days delayed developmental milestones and persistently enlarging head since birth. Child was previously operated at the age of 2 months for the correction of anal atresia and rectovaginal fistula. Child was born out of non- consanguineous marriage to a 25 year old mother by caesarean section in view of foetal distress with breech presentation. The documented birth weight of the child was $2.6 \mathrm{Kg}$.

There were few congenital deformities documented at birth namely, imperforate anus, rectovaginal fistula, right club foot and scoliosis.

The pedigree analysis revealed done spontaneous abortion in the generation previous to the affected child. The child has a 3 year old brother who had no similar complains( Fig 1).

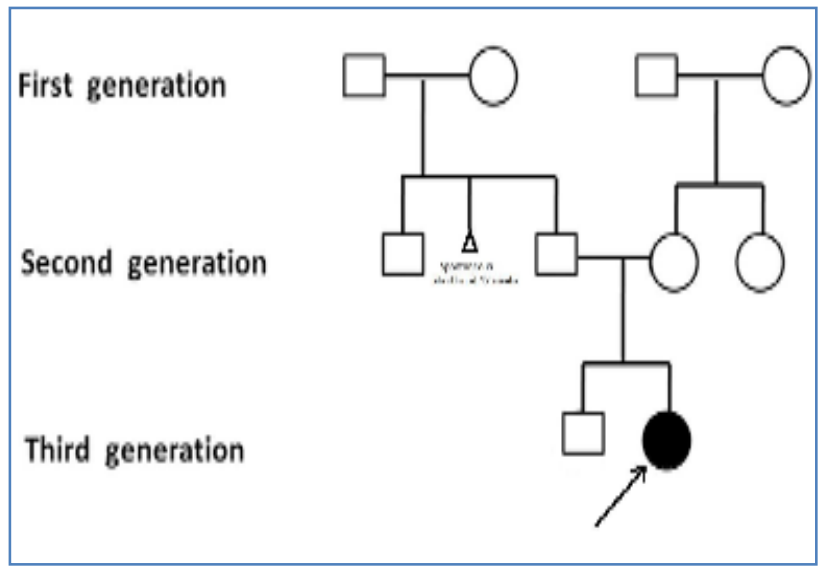

Figure 1: Pedigree analysis

The obstetric history of the mother revealed no history of still births or spontaneous abortions. The mother did not undergo any antenatal scan. There was no significant history of any fever, rash, drug intake, tuberculosis, diabetes mellitus, or radiation exposure during pregnancy. There was no history of difficulty in feeding or choking during feeding. There was no history of prior blood transfusions.

The diagnosis of VACTERL-H syndrome was made based on the above clinical, radiological and laboratory findings (Table 1).

Clinical examination of the child revealed a head circumference of $50 \mathrm{~cm}$ which was more than $2 \mathrm{SD}$ for age suggesting macrocephaly (Fig 2 ).

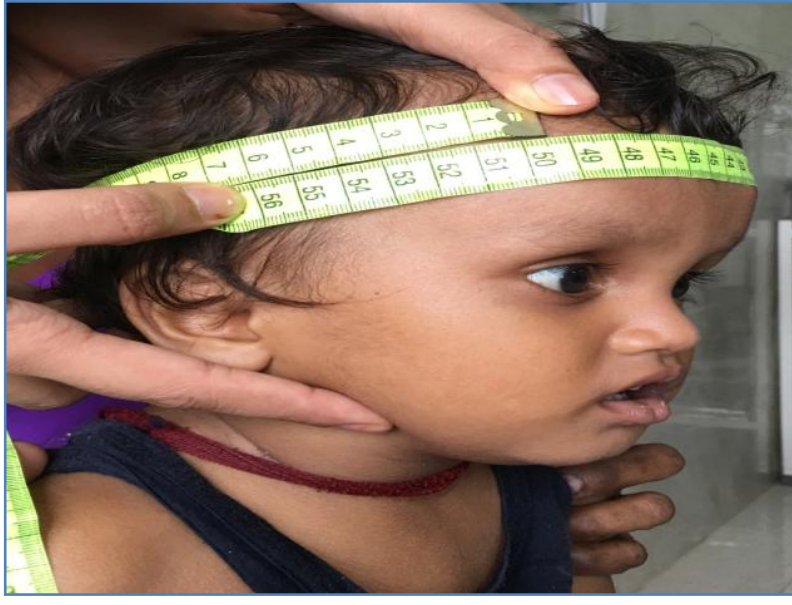

Figure 2: Measurement of head circumference.

Developmental quotient was less than $50 \%$ in all domains. Left sided pre-auricular ear tag was noted. Scoliosis was noted with concavity to left and convexity to right. The rib cage on the left side was deformed on palpation. We were able to pass $6 \mathrm{Fr}$ nasogastric tube through the anus with difficulty. Right CTEV foot was noted (Fig 3).

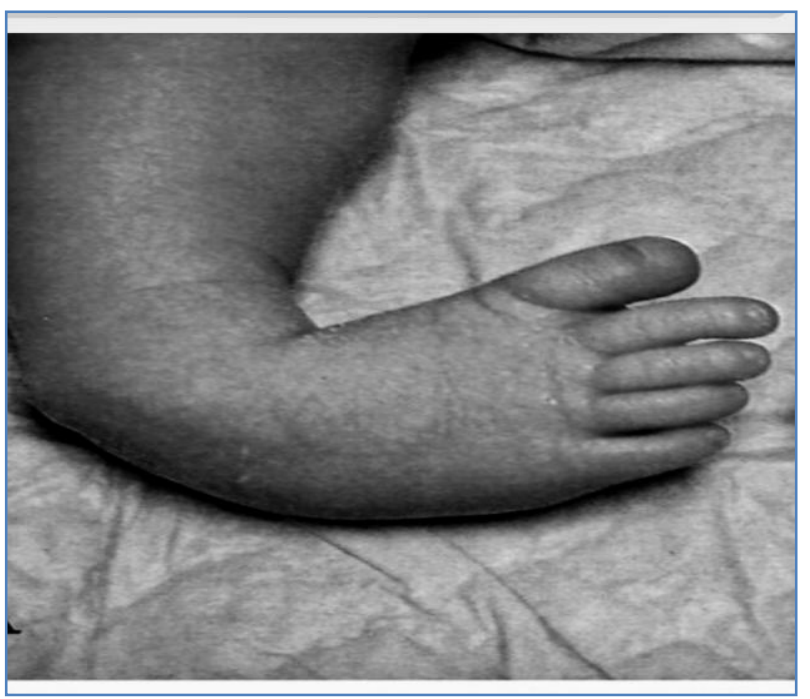

Figure 3: Showing the right CTEV

Ultrasonography of abdomen revealed solitary right kidney and left renal agenesis. Right kidney normal in size and echotexture.

Erect X-ray of Abdomen, P/A view was done. It revealed multiple hemivertebrae in thoracic and lumbar regions. Bifid ribs were noted in the right thoracic cage. Multiple ribs were absent from the right thoracic cage. 13 ribs on left side in place of 13 pair were seen in left thoracic cage. Scoliosis was noted with concavity to the left side (Fig. 4). 


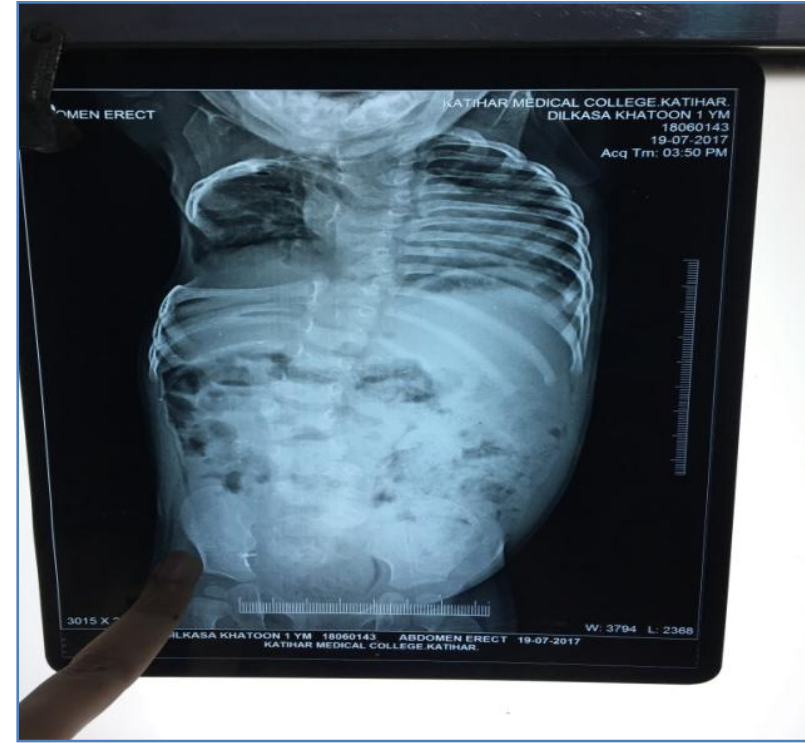

Figure 4: Erect $X$-ray of Abdomen, P/A view

Non contrast CT scan of brain revealed grossly dilated 3 rd ventricle and both lateral ventricles. However, 4th ventricle was normal and in midline. The septum pellucidum was absent. The brain parenchyma in both cerebral hemispheres is compressed. Hence NCCT of brain was suggestive of severe obstructive hydrocephalus likely to be congenital aqueductal stenosis (Fig. 5).

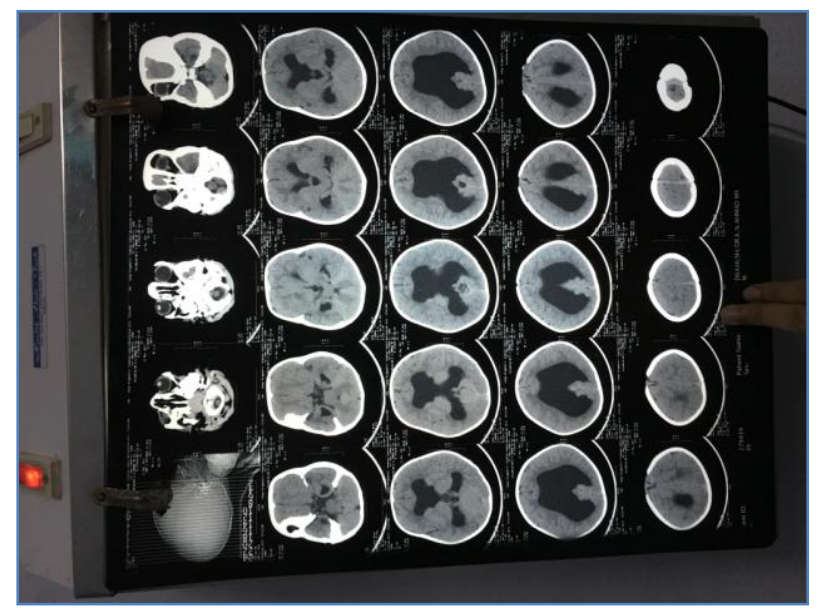

Figure 5: NCCT of brain was suggestive of severe obstructive hydrocephalus.

Echocardiography of the patient was unremarkable. There was no evidence of pancytopenia in complete blood counts.

Patient was provided pediatric surgery consultation for the follow up management of anorectoplasty. Patient was referred to pediatric neurosurgery centre for the management of obstructive hydrocephalus. Patient was also referred to Pediatric genetic centre for chromosomal and genetic studies.

\section{DISCUSSIONS}

VACTERL (vertebral, anal, cardiac, tracheoesophagus, renal, and limbs) is an abbreviation for the congenital group of abnormalities, including vertebral or vascular anomalies, anal atresia, cardiac defects, tracheoesophageal - fistula/esophageal atresia, renal defects, and limbs defects. It is a rare association and not accidental event where several organs are affected by developmental defects during blastogenesis.

All the features of VACTERL association may occur in a patient with fanconi anaemia, but radial-ray defects, haematological problems such as bone marrow failure and pigmentation anomalies are considered as distinct features [8] .

Defects may include cleft lip and cleft palate, hypothyroidism, duodenal atresia or stenosis, abnormalities of genital and urinary system, and anomalies of the respiratory, intestinal, vascular and central nervous system [8].

These features were not present in this present case. VACTERL-type anomalies have been increasingly described in proven cases of Fanconi anaemia [8]. Hence chromosomal breakage studies should be done in patients with the VACTERL phenotype, especially with radial anomalies and if there are features suggestive of Fanconi anaemia [1, 7]. The overlapping of defects of VACTERL association has also been described with Pallister-Hall syndrome, Towne-Brocks syndrome, 22q11.2 deletion syndrome and MURCS association which is characterized by the presence of Müllerian duct aplasia, renal aplasia and cervico-thoracic somite dysplasia [1].

The combination of VACTERL abnormalities may present with some known chromosomal abnormalities, including trisomy 13, 18, 21 and $5 p$ syndrome [5].

Embryological studies suggest that VACTERL has multiple polytopic developmental field defects [1]. A disruption in differentiating mesoderm in the first 45 weeks may lead to the different malformations of the VACTERL spectrum, including the presence of a SUA. Other aetiological factors may include diabetic mother, infertility treatment, and exposure to oestrogen or progesterone containing compounds, lead, anticonvulsants, folic acid antagonists or alcohol during the period of embryogenesis causing mutations in the genes namely ZIC3, HOXD13 and FOXF1. These factors may also result mitochondrial 
mutations leading to defective development of different anatomical structures of the embryo [1].

VACTERL with hydrocephalus is an extremely rare disorder that affects males and females equally [2]. Most of the cases of classical VACTERL occur sporadically; however chromosomal abnormalities have also been described in a few cases [4]. VACTERL with hydrocephalus is probably inherited as an autosomal recessive trait. [2] Genetic counselling of the family is needed. [2, 9] Fanconi anaemia is a major association of VACTERL-H. [4]. Antenatal ultrasonography is diagnostic. [4] Treatment starts from birth and includes systematic integrated multidisciplinary approach and timely surgical correction of the defects as well as nutritional support measures pre- and post - operatively [4].

The etiology of the hydrocephalus in VACTERL-H is variable namely congenital aqueductal stenosis, arnold chiari malformation or non- progressive ventriculomegaly. $[1,5]$ VACTERL-H has worse prognosis due to the neuro-disability, which is rare in classical VACTERL.[5]

Mutation in PTEN locus is found in VACTERL-H syndrome. [1,5] Cytogenetic analysis has research prospects and should be done in a VACTERL-H patient[5].

\section{CONCLUSIONS}

VACTERL syndrome cases are seen very rarely. The diagnosis of VACTERL-H Syndrome is majorly based upon the complete physical examination and a few specialized tests to ascertain the features of the syndrome. The treatment of VACTERL-H is directed towards the specific symptoms that are apparent in each individual, which often varies greatly. Hence early diagnosis and early interventions are needed to prevent morbidity and mortality.

\section{REFERENCES}

1. Solomon BD. VACTERL/VATER Association. Orphanet J Rare Dis. 2017 October 16; 6 : 56.

2. Konstantinidis A., Emmerson A. VACTERLH syndrome. Infant 2013; 9(5): 158-61.1.

3. Orphanet Report Series - Prevalence of rare diseases: Bibliographic data -July 2019 - Number 2http://www.orpha.net/orphacom/cahiers/docs/GB/ Prevalence_of_rare_diseases_by_decreasing_prevela nce_or_casesaccessed on :30/7/19

4. Rittler M, Paz JE, Castilla EE: VACTERL association, epidemiologic definition and delineation. Am J Med Genet 1996; 63 : 529-536.

5. Reardon $W$, Zhou XP, Eng C. A novel germline mutation of the PTEN gene in a patient with macrocephaly, ventricular dilatation and features of VATER association. J Med Genet 2001;38 : 820-3.

6. Castori M, Rinaldi R, Cappellacci S, Grammatico P. Tibial development field defect is the most common lower limb malformation pattern in VACTERL association. Am J Med Genet A 2008; 146A : 1259-66.

7. La Placa S, Giuffre' $M$, Gangemi A, Di Noto S, Matina $F$, Nociforo F,et al. Esophageal atresia in newborns: a wide spectrum from the isolated forms to a full VACTERL phenotype, Ital J Pediatr 2013; $39: 45$.

8. Faivre L, Portnol " MF, Pal G, Stoppa-Lyonnet D, Le Merrer M,Thauvin-Robinet $C$, et al. Should chromosome breakage studies be preformed in patients with VACTERL associationAm J Med Genet A 2005;137: 55-8.

9. Hilger $A$, Schramm C, Draaken $M$, Mughal SS, Dworschak G, Bartels E,et al. Familial occurrence of the VATER/VACTERL association. Pediat Surg Int 2012;28 : 725-9. 